\title{
Gas chromatography-mass spectroscopy analysis of a Xanthorrhoea johnsonii leaf extract displaying apparent anaesthetic effects
}

\author{
Ian E. Cock ${ }^{1,2}$, Frederick R. Kalt ${ }^{2}$
}

\begin{abstract}
Background: Xanthorrhoea johnsonii A. T. Lee is a slow growing endemic Australian plant species. Its slow growth rate and lack of use by herbivores as a food source indicate that its leaves may contain chemical deterrents. Materials and Methods: $X$. johnsonii leaf extracts were tested for toxicity using the Artemia franciscana nauplii bioassay. Toxic extracts were further analysed by RP-HPLC and gas chromatographymass spectroscopy (GC-MS). Results: As well as toxicity, anaesthetic/sedative effects were also noted in the methanolic and ethyl acetate extracts. A. franciscana nauplii 'died' following a $12 \mathrm{~h}$ exposure to these extracts, only to 'recover' and swim normally by $48 \mathrm{~h}$ exposure. By $60 \mathrm{~h}$ the $X$. johnsonii methanol/ethyl acetate extract exposed nauplii were again experiencing toxic effects and the mortality began to increase. The nauplii did not recover from this moribund state a second time. Analysis of these extracts by RP-HPLC showed that the ethyl acetate extract was the least complex of the toxic extracts. Subsequent analysis of this extract by GC-MS revealed that it contained 12 main compounds: O-hydroxycinnamic acid; acetic acid; 2,2-dimethoxybutane; pinacol; 4-methyl-1,3-dioxane; decane, 2,2-dimethylbutane; 2,5,9-trimethyldecane; 1,2-benzenediol; 1,2,3-benzenetriol; benzoic acid and an unidentified compound. Conclusion: These results confirm the toxicity and anaesthetic/sedative effects of $X$. johnsonii leaf components and highlight o-hydroxycinnamic acid as the likely compound responsible for this bioactivity.
\end{abstract}

Key words: Anaesthetic, Artemia franciscana bioassay, coumaric acid, grass tree, o-hydroxycinnamic acid, sedative, Xanthorrhoea johnsonii, Xanthorrhoeaceae

\author{
${ }^{1}$ Environmental Futures Centre, \\ ${ }^{2}$ Biomolecular and Physical \\ Sciences, Nathan Campus, \\ Griffith University, \\ 170 Kessels Road, Nathan, \\ Queensland 4111, Australia
}

Access this article online

Website: www.jnatpharm.org DOl: 10.4103/2229-5119.102749

Quick Response Code:

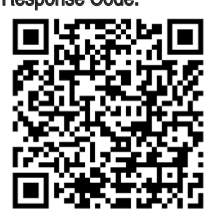
Address for correspondence: Dr. Ian Cock, Biomolecular and Physical Sciences, Griffith University, Nathan Campus, 170 Kessels Road, Nathan, Queensland-4111, Australia. E-mail: I.Cock@griffith.edu.au

\section{INTRODUCTION}

Xanthorrhoea (commonly known as grass trees) is a small genus of Australian native plants consisting of 28 species, all of which are endemic to Australia. ${ }^{[1]}$ All members of this genus are extremely long lived. Indeed, the age of some Xanthorrhoea plants have been estimated at nearly 600 years. ${ }^{[1,2]}$ These plants are also extremely slow growing, with the growth of Xanthorrhoea johnsonii A. T. Lee estimated to be substantially less than 1 $\mathrm{cm} /$ year. ${ }^{[2]}$ Some members of the genus remain stemless, having the appearance of coarse tufts of rigid grass. Other species develop a thick trunk which is topped by a dense crown of rigid leaves. $X$. johnsonii is one such example of a trunk forming species. It has been estimated that it may take up to 20 years for trunk formation to occur in some plants..$^{[2]}$

Being such a slow growing genus, it is likely that Xanthorrhoea's may have developed protective mechanisms to deter animal foraging which could potentially threaten their survival. The morphology of plants of this genus suggests that any such protective mechanism is not physical in nature. Xanthorrhoea's have no spines, prickles or other physical mechanisms of protection. Whilst the leaves of some species are coarse, it is unlikely that they are tough enough to deter foraging animals. It is therefore possible that some Xanthorrhoea species may have developed chemical deterrents. This hypothesis is supported by the small number of animals that use Xanthorrhoea leaves as a food source. Although several species of insects, birds and mammals feed on Xanthorrhoea spp., they almost exclusively eat the flowers and seeds, leaving the leaves largely untouched..$^{[1]}$ Indeed, the only reports of animals feeding on significant quantities of Xanthorrhoea leaves were studies examining poisoning of cattle grazing on their leaves. ${ }^{[3]}$ Cattle grazing on Xanthorrhoea leaves became uncoordinated and dehydrated. They 
[Downloaded free from http://www.jnatpharm.org on Wednesday, February 27, 2013, IP: 132.234.251.230] || Click here to download free Android application for this journal

Cock and Kalt: Identification of anaesthetic components in Xanthorrhoea johnsonii leaf extracts

lost weight and if not stopped from eating the leaves, often died. This indicates that a chemical protectant/deterrent present in Xanthorrhoea leaves may be responsible for discouraging foraging herbivores, allowing juvenile plants to grow to maturity.

Recent studies from our laboratory tested this hypothesis by examining $X$. johnsonii leaves for toxicity using the Artemia franciscana nauplii (brine shrimp larvae) lethality bioassay. ${ }^{[4,5]}$ Whilst significant toxicity was detected in methanolic extracts of the leaves of $X$. johnsonii in those studies, another unexpected bioactivity was also reported. The extract had an apparent anaesthetic effect. Although the $X$. johnsonii methanolic extract initially appeared to rapidly kill the $A$. franciscana nauplii, they were able to recover by $48 \mathrm{~h}$ of exposure. This effect was compared to the effects previously described for tubocurarine, dimethyltubocurarine and alcuronium (collectively known as curare, a South American arrow poison) from Chondrodendron tomentosum. ${ }^{[6]}$ Curare is a neuromuscular blocker that was commonly used as a muscle relaxant by anaestheologists prior to the development of safer, more effective muscle relaxants. It functions by blocking neuronal nicotinic acetylcholine receptors (nAChR), thus blocking neurotransmission. ${ }^{[7]}$ However, our earlier study did not determine the chemical composition of the $X$. johnsonii methanolic extract.

The current report was undertaken to extend the previous studies into the anaesthetic effect of $X$. johnsonii leaf methanolic extract and to structurally characterise the phytochemical composition of a bioactive extract. Extraction with a variety of solvents with different polarities was used to differentially extract different components. gas chromatography-mass spectroscopy (GC-MS) analysis was used to identify any known components in an active extract.

\section{MATERIALS AND METHODS}

\section{Plant collection and extraction}

$X$. johnsonii is one of only two species of Xanthorrhoea occurring naturally in Toohey Forest, Australia. It is easily distinguished from the other species as $X$. johnsonii is the only trunk forming species occurring in that area. $X$. johnsonii leaves were collected from Toohey Forest and were identified with reference to a taxonomic key to Toohey Forest plants. ${ }^{[8]}$ Samples were dried in a Sunbeam food dehydrator and then ground to a coarse powder. $1 \mathrm{~g}$ of plant material was weighed into each of five tubes and five different extracts were prepared by adding $50 \mathrm{ml}$ of methanol, water, ethyl acetate, chloroform, or hexane respectively. All solvents were obtained from Ajax and were AR grade. Leaf material was extracted in each solvent for $24 \mathrm{~h}$ at $4^{\circ} \mathrm{C}$ with gentle shaking. The extracts were filtered through filter paper (Whatman No. 54) under vacuum, followed by drying by rotary evaporation in an Eppendorf concentrator 5301. The resultant dry extract was weighed and redissolved in $10 \mathrm{ml}$ deionised water.

\section{Qualitative phytochemical studies}

Phytochemical analysis of $X$. johnsonii extracts was conducted by previously described qualitative assays ${ }^{[9,10]}$ and are briefly outlined below.

\section{Saponins}

$1 \mathrm{~mL}$ of pure extract was added to $1 \mathrm{~mL}$ deionised water and shaken vigorously for $30 \mathrm{~s}$. The tubes were allowed to stand for $15 \mathrm{~min}$ and the presence or absence of persistent frothing was noted. Persistent frothing indicated the presence of saponins.

\section{Phenolic compounds}

Phenolic compounds were detected using a modified version of the Folin-Ciocalteu procedure. ${ }^{[9,10]} 200 \mu \mathrm{L}$ of crude extract was added to $2 \mathrm{~mL}$ of $3 \%$ aqueous sodium carbonate, followed by the addition of $200 \mu \mathrm{L}$ FolinCiocalteu reagent. The mixture was allowed to stand for $30 \mathrm{~min}$ at room temperature. The formation of blue/gray colour indicated the presence of phenolic groups.

Water soluble phenol test

2 drops of $1 \%$ ferric chloride were added to $500 \mu \mathrm{L}$ of each extract. A red colour change indicated the presence of water soluble phenols.

Water insoluble phenol test

$500 \mu \mathrm{L}$ of dichloromethane, 3 drops of $1 \%$ ferric chloride and 1 drop of pyridine were added to $500 \mu \mathrm{L}$ of each extract and mixed. The presence of insoluble phenols was indicated by a colour change.

\section{Flavonoids}

$100 \mu \mathrm{L}$ of aqueous sodium hydroxide was added to $1 \mathrm{~mL}$ of each extract. The development of an intense yellow colour indicated the presence of flavonoids. $100 \mu \mathrm{L}$ of concentrated $\mathrm{HCl}$ was added to the solution. Reversion to the original colour confirmed the presence of flavonoids.

\section{Polysteroids}

Three drops of acetic anhydride was added to $500 \mu \mathrm{L}$ of crude extract, followed by the addition of a few drops concentrated sulphuric acid. The solution was allowed to sit at room temperature for 5 min. Formation of a blue/green colour indicated the presence of polysteroids.

\section{Triterpenoids}

$1 \mathrm{~mL}$ of extract was slowly added to $400 \mu \mathrm{L}$ chloroform, followed by careful addition of $400 \mu \mathrm{L}$ concentrated sulphuric acid. Formation of a red/brown/purple colour at the interface indicated the presence of triterpenoids. 
[Downloaded free from http://www.jnatpharm.org on Wednesday, February 27, 2013, IP: 132.234.251.230] || Click here to download free Android application for this journal

Cock and Kalt: Identification of anaesthetic components in Xanthorrhoea johnsonii leaf extracts

\section{Cardiac glycosides}

$500 \mu \mathrm{L}$ of extract was added to $500 \mu \mathrm{L}$ glacial acetic acid. A few drops of $1 \%$ aqueous iron chloride and concentrated sulphuric acid were then carefully added. The presence of a red/brown ring of the interface or the formation of a green/blue colour throughout the solution indicates the presence of cardiac glycosides.

\section{Anthraquinones}

The modified Kumar test ${ }^{[9,10]}$ involved addition of a few drops of concentrated sulphuric acid to $500 \mu \mathrm{L}$ pure extract, followed by the careful addition of $500 \mu \mathrm{L}$ of ammonia. A rose pink colour indicates the presence of free anthraquinones. For the Ajaiyeoba test, ${ }^{[9,10]} 450 \mu \mathrm{L}$ of crude extract was added to $50 \mu \mathrm{L}$ concentrated $\mathrm{HCl}$ and allowed to stand at room temperature for several minutes. $500 \mu \mathrm{L}$ chloroform was then carefully added. The formation of a rose pink colour indicates the presence of combined anthraquinones.

\section{Tannins}

Two drops of $1 \%$ aqueous ferric chloride reagent were added to $500 \mu \mathrm{L}$ of crude extract. The mixture was observed for the formation of blue, blue-black, green or green-black colouration which indicated the presence of tannins.

\section{Alkaloids}

Two methods were used to test for the presence of alkaloids:

\section{Mayer's reagent test}

$200 \mu \mathrm{L}$ of pure extract was treated with a few drops of aqueous solution of hydrochloric acid and $500 \mu \mathrm{L}$ Mayer's reagent. Formation of a white precipitate was taken to indicate the presence of alkaloids.

Mayer's reagent: Mercuric chloride (1.358 g) was dissolved in $60 \mathrm{~mL}$ deionised water. Potassium Iodide $(5.0 \mathrm{~g})$ was dissolved in $10 \mathrm{~mL}$ deionised water. The mercuric chloride and potassium iodide solutions were mixed and made up to $100 \mathrm{~mL}$ with deionised water.

\section{Uagner's reagent test}

$200 \mu \mathrm{L}$ of each extract was treated with a few drops of an aqueous solution of hydrochloric acid and $500 \mu \mathrm{L}$ Wagner's reagent. A reddish-brown flocculent precipitate indicated the presence of alkaloid.

Wagner's reagent: $1.27 \mathrm{~g}$ Iodine and $2 \mathrm{~g}$ Potassium Iodide were dissolved in $5 \mathrm{~mL}$ deionised water and made up to final volume $100 \mathrm{~mL}$ with deionised water.

\section{Toxicity screening}

\section{Reference toxins for biological screening}

Potassium dichromate $\left(\mathrm{K}_{2} \mathrm{Cr}_{2} \mathrm{O}_{7}\right)$ (AR grade, ChemSupply, Australia) was prepared as a $1.6 \mathrm{mg} / \mathrm{mL}$ solution in distilled water and was serially diluted in synthetic seawater for use in the $A$. franciscana nauplii bioassay. Mevinphos (2-methoxycarbonyl-1-methylvinyl dimethyl phosphate) was obtained from Sigma-Aldrich as a mixture of cis (76.6\%) and trans (23.0\%) isomers and prepared as a $4 \mathrm{mg} / \mathrm{mL}$ stock in distilled water. The stock was serially diluted in artificial seawater for use in the bioassay.

\section{Artemia franciscana nauplii toxicity screening}

Toxicity was tested using the $A$. franciscana nauplii lethality assay developed for the screening of active plant constituents. The assay was modified as previously described. ${ }^{[11-13]}$ Briefly, A. franciscana cysts were obtained from North American Brine Shrimp, LLC, USA (harvested from the Great Salt Lake, Utah). Synthetic seawater was prepared using Reef Salt, AZOO Co., USA. Seawater solutions at $34 \mathrm{~g} / \mathrm{L}$ distilled water were prepared prior to use. $2 \mathrm{~g}$ of $A$. franciscana cysts were incubated in $1 \mathrm{~L}$ synthetic seawater under artificial light at $25^{\circ} \mathrm{C}, 2000 \mathrm{Lux}$ with continuous aeration. Hatching commenced within 16-18 h of incubation. Newly hatched A. franciscana (nauplii) were used within $10 \mathrm{~h}$ of hatching. Nauplii were separated from the shells and remaining cysts and were concentrated to a suitable density by placing an artificial light at one end of their incubation vessel and the nauplii rich water closest to the light was removed for biological assays. $400 \mu \mathrm{L}$ of seawater containing approximately 46 (mean $46.1, n=140$, SD 18.7) nauplii were added to wells of a 48 well plate and immediately used for bioassay. The plant extracts were diluted to 4 $\mathrm{mg} / \mathrm{mL}$ in seawater for toxicity testing, resulting in a 2 $\mathrm{mg} / \mathrm{mL}$ concentration in the bioassay. $400 \mu \mathrm{L}$ of diluted plant extract and the reference toxins were transferred to the wells and incubated at $25 \pm 1^{\circ} \mathrm{C}$ under artificial light (1000 Lux). A negative control (400 $\mu \mathrm{L}$ seawater) was run in triplicate for each plate. All treatments were performed in at least triplicate. The wells were checked at regular intervals and the number of dead counted. The nauplii were considered moribund if no movement of the appendages was observed within 10 sec. After $72 \mathrm{~h}$ all nauplii were sacrificed and counted to determine the total number per well. The $\mathrm{LC}_{50}$ with $95 \%$ confidence limits for each treatment was calculated using probit analysis.

\section{Reverse phase high performance liquid chromatography}

Gradient reverse phase high performance liquid chromatography (RP-HPLC) was performed at a flow rate of $1 \mathrm{mg} / \mathrm{mL}$ using dual LC-10 AT VP pumps (Shimadzu HPLC class VP series), a variable wavelength programmable photodiode array detector SPD MIOA VP 
[Downloaded free from http://www.jnatpharm.org on Wednesday, February 27, 2013, IP: 132.234.251.230] || Click here to download free Android application for this journal

Cock and Kalt: Identification of anaesthetic components in Xanthorrhoea johnsonii leaf extracts

(Shimadzu), a CTO-IOAS VP column oven (Shimadzu), an SCL-10A VP system controller (Shimadzu) and a BioRad reverse phase $\mathrm{C}_{18}$ column $(150 \mathrm{~mm} \times 4.6 \mathrm{~mm})$. The HPLC system was equipped with software class VP series version 6.12 (Shimadzu). The gradient was performed as follows: 5 min $0 \%$ methanol, followed by a 10 min gradient to $5 \%$ methanol. This was followed by a 10 min gradient to $20 \%$ methanol; 5 min gradient to $100 \%$ methanol; $100 \%$ methanol for $5 \mathrm{~min}$; $5 \mathrm{~min}$ gradient to $0 \%$ methanol. The column temperature was maintained at $24^{\circ} \mathrm{C}$ throughout. A $20 \mu \mathrm{L}$ sample was injected using the autoinjector (Shimadzu). $20 \mu \mathrm{L}$ of deionised water was used as a negative control to produce the baseline curve and zero the machine prior to each experiment.

\section{Gas chromatography-mass spectroscopy}

$X$. johnsonii leaf extract was diluted to $1 \mathrm{mg} / \mathrm{mL}$ and $0.5 \mu \mathrm{L}$ was separated on a nonpolar DB5-HT capillary column $(20 \mathrm{~m} \times 0.18 \mathrm{~mm})$ with a $0.1 \mu \mathrm{m}$ film (J and W Scientific) fitted to an AutoSystem XL GC-MS. The injector temperature was $270^{\circ} \mathrm{C}$ and the oven temperature was programmed at an initial temperature of $50^{\circ} \mathrm{C}$ for $1 \mathrm{~min}$, rising at $25^{\circ} \mathrm{C}$ per minute to $160^{\circ} \mathrm{C}$ and maintained at that temperature for $1 \mathrm{~min}$. The temperature was subsequently increased by $10^{\circ} \mathrm{C}$ per min to $300^{\circ} \mathrm{C}$ and maintained at that temperature for a further $4.6 \mathrm{~min}$. The carrier gas was helium at a constant pressure of $5 \mathrm{kPa}$. The GC was directly interfaced with an AutoSystem XL quadrapole mass spectrometer with an interface temperature of $270^{\circ} \mathrm{C}$. Sample ionisation was by $70 \mathrm{eV}$ electron impact and was analysed in positive mode. Structural determination was by comparison of mass spectral patterns to ChemSpider data bases.

\section{Statistical analysis}

Bioactivity data are expressed as the mean \pm standard error of at least three independent experiments.

\section{RESULTS}

\section{Liquid extraction yields and qualitative phytochemical screening}

Extraction of $1 \mathrm{~g}$ of dried plant material with various solvents yielded dried plant extracts ranging from $40 \mathrm{mg}$ to $264 \mathrm{mg}$ [Table 1]. Chloroform gave the highest yield of dried extracted material $(264 \mathrm{mg})$ whilst ethyl acetate extracted the lowest mass $(40 \mathrm{mg})$. The dried extracts were resuspended in $10 \mathrm{~mL}$ of deionised water for further analysis, resulting in the extract concentrations shown in Table 1.

Phytochemical studies [Table 2] show that methanol and water extracted the widest range of phytochemicals from $X$. johnsonii leaves. Both extracts showed moderate to high levels of water soluble phenolics and low levels of water insoluble phenolics. Moderate to high levels of saponins, triterpenes and flavanoids were also detected in these extracts. The methanol and water extracts also contained low but detectable levels of cardiac glycosides, tannins and anthraquinones. The ethyl acetate, chloroform and hexane extracts all only had detectable levels of water insoluble phenols and saponins.

\section{Quantification of toxicity}

X.johnsonii extracts were diluted to $2000 \mu \mathrm{g} / \mathrm{mL}$ in artificial seawater for toxicity testing, resulting in a $1000 \mu \mathrm{g} / \mathrm{mL}$ concentration in the $A$. franciscana lethality bioassay. For comparison, the reference toxins potassium dichromate $(800 \mu \mathrm{g} / \mathrm{mL})$ and Mevinphos $(2000 \mu \mathrm{g} / \mathrm{mL})$ were also tested in the bioassay. The potassium dichromate [Figure 1f] and Mevinphos [Figure 1g] positive controls both induced the onset of mortality within $24 \mathrm{~h}$ of exposure, with $100 \%$ mortality induction by $36 \mathrm{~h}$. In agreement with previous reports, ${ }^{[4]}$ the $X$. johnsonii methanol extract [Figure 1a] induced apparent morbundity very rapidly. Indeed, $87.8 \pm 0.9 \%$ apparent morbundity was seen at $12 \mathrm{~h}$, with $100 \%$ apparent morbundity at

\begin{tabular}{|c|c|c|}
\hline Solvent & $\begin{array}{l}\text { Mass of dried extract } \\
(\mathrm{mg})\end{array}$ & $\begin{array}{c}\text { Resuspended extract } \\
\text { concentration }(\mathrm{mg} / \mathrm{mL})\end{array}$ \\
\hline Methanol & 72 & 7.2 \\
\hline Deionised water & 114 & 11.4 \\
\hline Ethyl acetate & 40 & 4.0 \\
\hline Chloroform & 264 & 26.4 \\
\hline Hexane & 108 & 10.8 \\
\hline
\end{tabular}

\begin{tabular}{|c|c|c|c|c|c|c|c|c|c|c|c|c|c|c|}
\hline \multirow[t]{2}{*}{ Extract } & \multicolumn{3}{|c|}{ Phenols } & \multirow{2}{*}{$\begin{array}{c}\text { Glycosides } \\
\text { Keller- } \\
\text { Kiliani test }\end{array}$} & \multirow{2}{*}{$\frac{\text { Saponins }}{\text { Froth }}$} & \multirow{2}{*}{$\frac{\text { Triterpenes }}{\begin{array}{c}\text { Salkowski } \\
\text { test }\end{array}}$} & \multirow{2}{*}{$\begin{array}{l}\text { Phytosteroids } \\
\text { Acetic } \\
\text { anhydride test }\end{array}$} & \multicolumn{2}{|c|}{ Alkaloids } & \multicolumn{2}{|c|}{ Flavanoids } & \multirow{2}{*}{$\begin{array}{c}\text { Tannins } \\
\text { Ferric } \\
\text { chloride } \\
\text { test }\end{array}$} & \multirow{2}{*}{\multicolumn{2}{|c|}{$\frac{\text { Anthraquinones }}{\text { Free Combined }}$}} \\
\hline & $\begin{array}{c}\text { Total } \\
\text { phenolics }\end{array}$ & $\begin{array}{l}\text { Water } \\
\text { soluble }\end{array}$ & $\begin{array}{c}\text { Water } \\
\text { insoluble }\end{array}$ & & & & & $\begin{array}{l}\text { Meyers } \\
\text { test }\end{array}$ & $\begin{array}{l}\text { Wagners } \\
\text { test }\end{array}$ & $\begin{array}{l}\text { Shinoda } \\
\text { test }\end{array}$ & $\begin{array}{c}\text { Kumar } \\
\text { test }\end{array}$ & & & \\
\hline Methanol & ++ & ++ & + & + & ++ & ++ & - & - & - & ++ & ++ & + & - & + \\
\hline $\begin{array}{l}\text { Water } \\
\text { Ethyl }\end{array}$ & +++ & +++ & + & + & +++ & ++ & - & - & - & ++ & ++ & + & - & - \\
\hline acetate & + & - & + & - & + & - & - & - & - & - & - & - & - & + \\
\hline Chloroform & + & - & + & - & + & - & - & - & - & - & - & - & - & - \\
\hline Hexane & + & - & + & - & + & - & - & - & - & - & - & - & - & - \\
\hline
\end{tabular}

+++ indicates a large response, ++ indicates a moderate response; +indicates a minor response, -indicates no response in the assay 
[Downloaded free from http://www.jnatpharm.org on Wednesday, February 27, 2013, IP: 132.234.251.230] || Click here to download free Android application for this journal

Cock and Kalt: Identification of anaesthetic components in Xanthorrhoea johnsonii leaf extracts

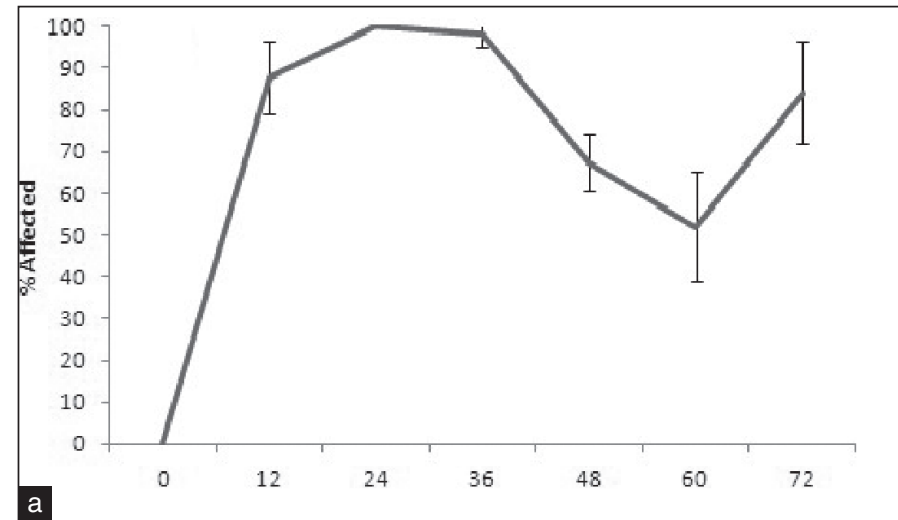

a
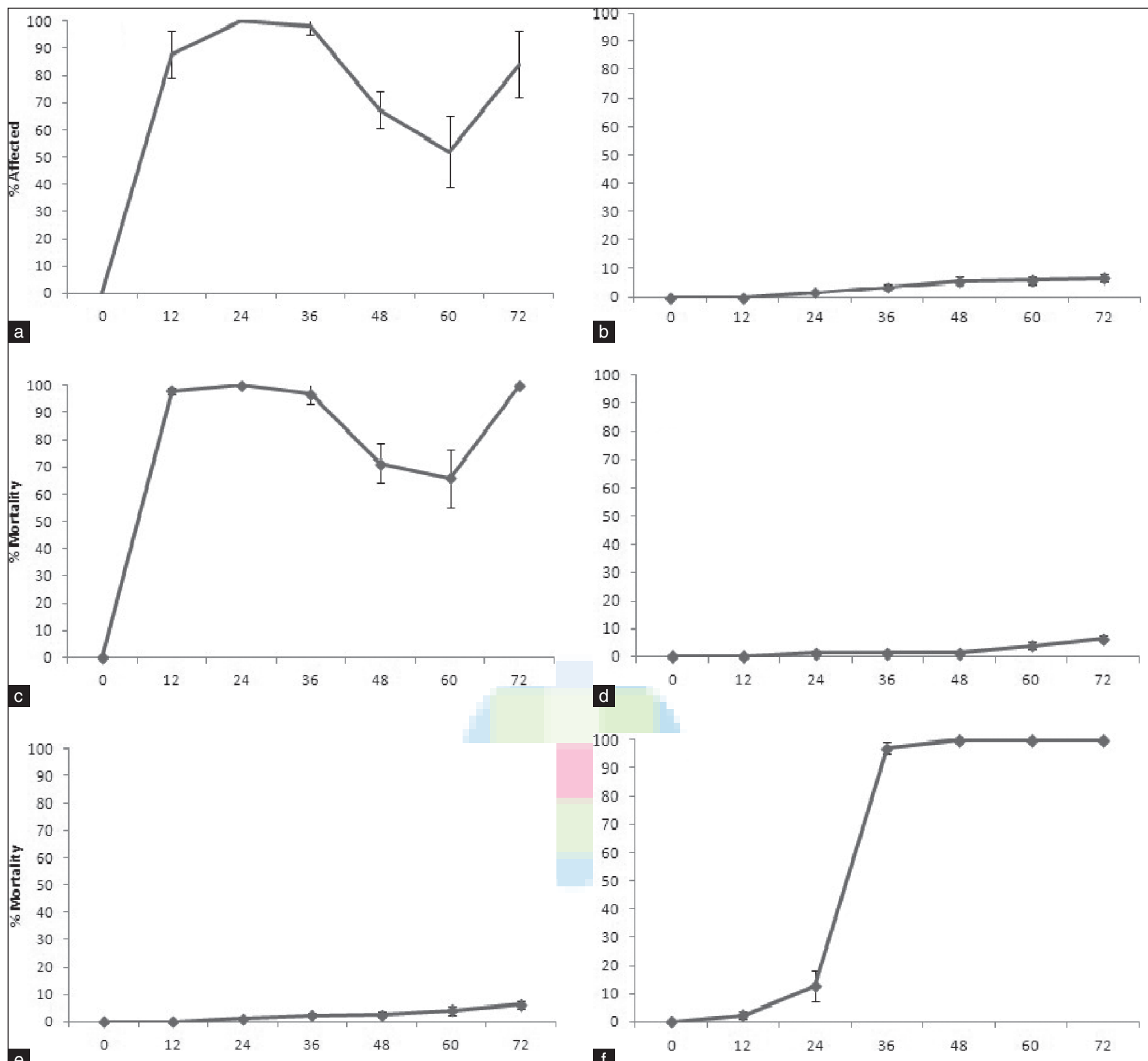

e
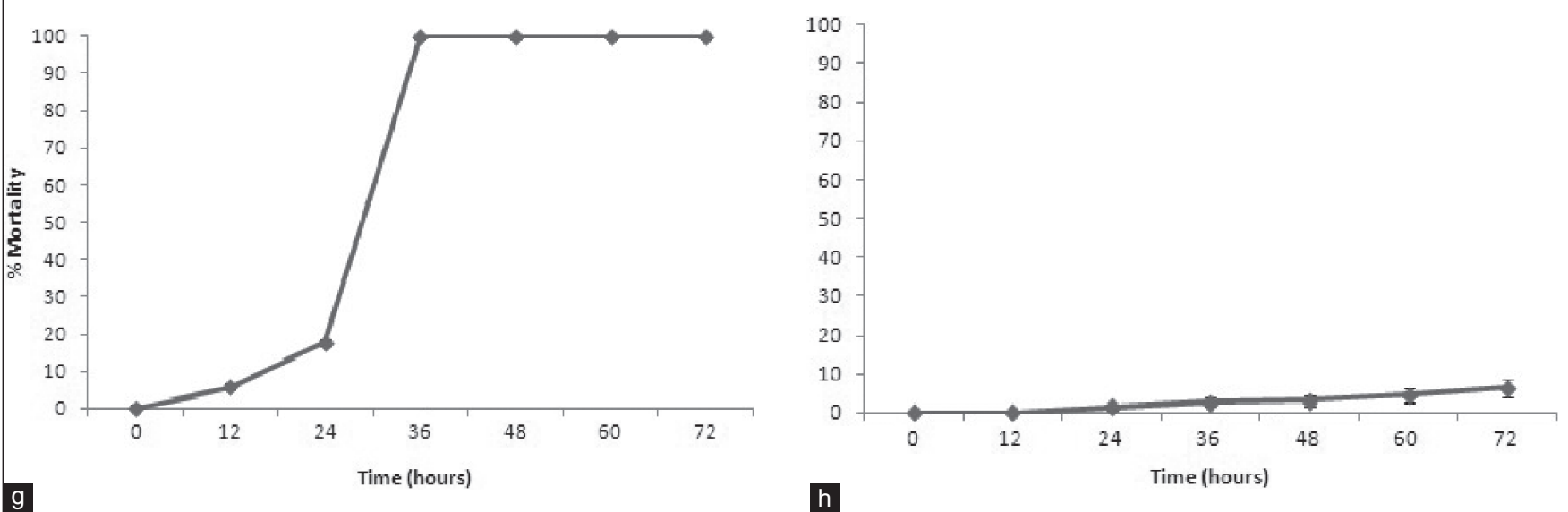

Figure 1: Brine shrimp lethality of (a) $X$. johnsonii methanol extract $(1000 \mu \mathrm{g} / \mathrm{mL})$, (b) $X$. johnsonii water extract $(1000 \mu \mathrm{g} / \mathrm{mL})$, (c) $X$. johnsonii ethyl acetate extract $(1000 \mu \mathrm{g} / \mathrm{mL})$, (d) $X$. johnsonii chloroform extract $(1000 \mu \mathrm{g} / \mathrm{mL})$, (e) $X$. johnsonii hexane extract $(1000 \mu \mathrm{g} / \mathrm{mL})$, (f) potassium dichromate $(800 \mu \mathrm{g} / \mathrm{mL})$, (g) Mevinphos $(2000 \mu \mathrm{g} / \mathrm{mL}$ ) and $(\mathrm{h})$ seawater control. All bioassays were performed in at least triplicate and are expressed as mean \pm standard error 
[Downloaded free from http://www.jnatpharm.org on Wednesday, February 27, 2013, IP: 132.234.251.230] || Click here to download free Android application for this journal

Cock and Kalt: Identification of anaesthetic components in Xanthorrhoea johnsonii leaf extracts

$24 \mathrm{~h}$. Also similar to our previous report was the decrease in apparent morbundity between $36 \mathrm{~h}$ and $60 \mathrm{~h}$ of exposure, reaching a minimum of $52.1 \pm 12.1 \%$ by $60 \mathrm{~h}$. A similar trend was evident for the ethyl acetate extract [Figure 1c] with approximately $100 \%$ apparent morbundity recorded at $12 \mathrm{~h}$, and a decrease in apparent morbundity to a minimum of $65.7 \pm 10.7 \%$ at $60 \mathrm{~h}$ of exposure. All other solvent extracts [Figures 1b,d,e] were nontoxic in the $A$. franciscana lethality bioassay, with no increase in apparent morbundity above that of the seawater control [Figure $1 \mathrm{~h}$ ].

Reverse phase high performance liquid chromatography analysis of extracts displaying apparent anaesthetic effects

The extracts which displayed apparent anaesthetic effects (ie. methanol and ethyl acetate extracts) were further analysed by RP-HPLC analysis. The methanol extract chromatogram [Figure 2a] revealed numerous overlapping peaks, particularly in the very early stages of the chromatogram corresponding to the elution of polar compounds. However, peaks at later stages of the chromatogram indicate the broad spread of polarities of the compounds in the methanol extract. In contrast, the ethyl acetate extract chromatograph [Figure $2 \mathrm{~b}$ ] revealed

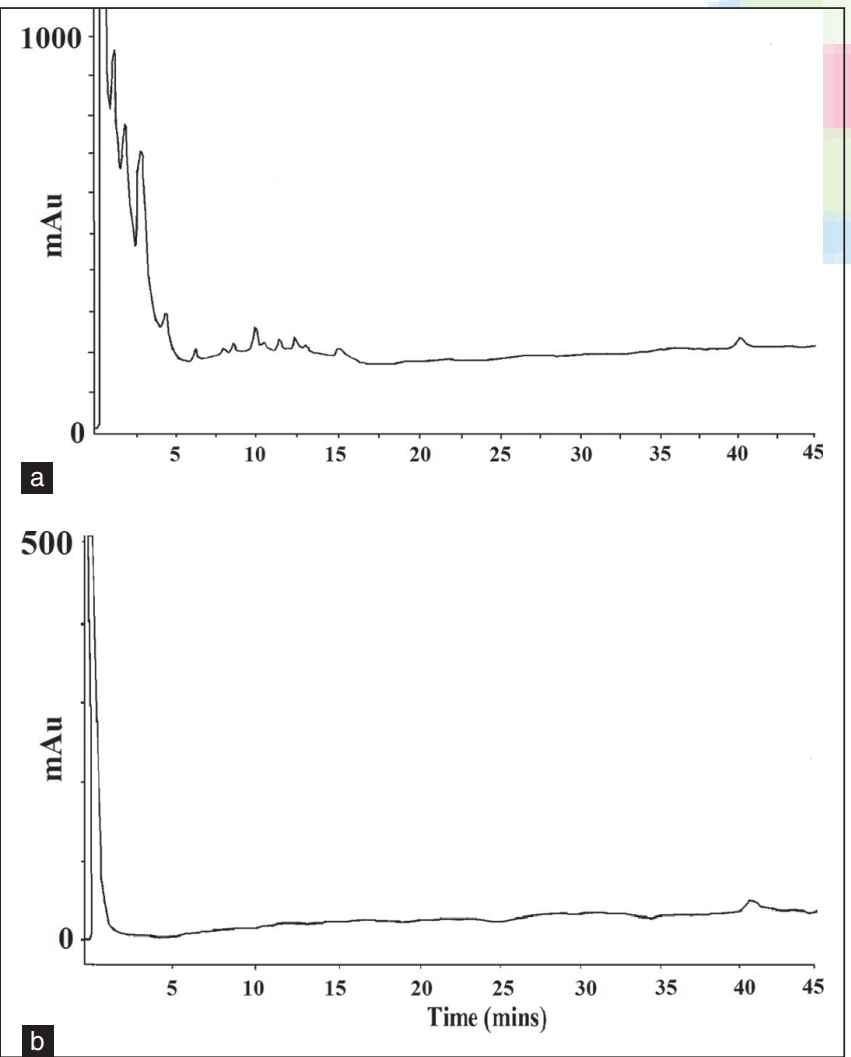

Figure 2: RP-HPLC chromatogram of (a) a $20 \mu \mathrm{L}$ injection of $X$. johnsonii methanol extract (dried and resuspended in deionised water), (b) $20 \mu \mathrm{L}$ injection of $X$. johnsonii ethyl acetate extract (dried and resuspended in deionised water). Absorbance was recorded at $210 \mathrm{~nm}$ and chromatography conditions were as described in the methods section much fewer peaks. The major peak eluted with the column void volume, indicating the polar nature of these compound(s). However, a minor peak was also evident eluting at higher methanol concentrations later in the chromatogram. As the ethyl acetate extract appeared to contain much fewer compounds yet still retained the same degree of bioactivity, this extract was deemed suitable for further analysis by GC-MS.

Gas chromatography-mass spectroscopy analysis of the $X$. johnsonii ethyl acetate extract

Gas chromatography of the ethyl acetate extract [Figure 3] resulted in the separation of 12 main peaks. These peaks were further analysed by mass spectroscopy [Figure 4]. Of the 12 peaks, structural identification was achieved for 11 compounds [Table 3]. The major peak from the gas chromatogram had a retention time of $3.22 \mathrm{~min}$. MS analysis [Figure 4e] determined the mass of this compound to be 142 and the empirical formula to be $\mathrm{C}_{10} \mathrm{H}_{22}$. A comparison with MS data bank ionisation patterns showed similarity with the 10 carbon hydrocarbon decane. Other compounds in the extract were determined to be the branched chain hydrocarbons 2,2-dimethylbutane (retention time 3.69 min; Figure 4f) and 2,5,9-trimethyldecane (retention time $3.88 \mathrm{~min}$; Figure $4 \mathrm{~g}$ ). Acetic acid (retention time 1.09; Figure 4a), 2,2-dimethoxybutane (retention time $1.57 \mathrm{~min}$; Figure 4b) and pinacol (retention time 1.69; Figure 4c) were also determined to be present in the extract. Benzoic acid (retention time 5.78; Figure 4k) and the benzene alcohols 1,2-benzenediol (retention time 4.59; Figure 4i) and 2,5,9-trimethyldecane (retention time 5.43; Figure 4j) were also detected. Also identified were 4-methyl-1,3-dioxane (retention time 2.19; Figure 4d) and o-hydroxycinnamic acid (retention time 4.37; Figure 4h). A definitive MS was not able to be obtained for the compound with a retention time of $6.24 \mathrm{~min}$, therefore we were unable to indentify this compound.

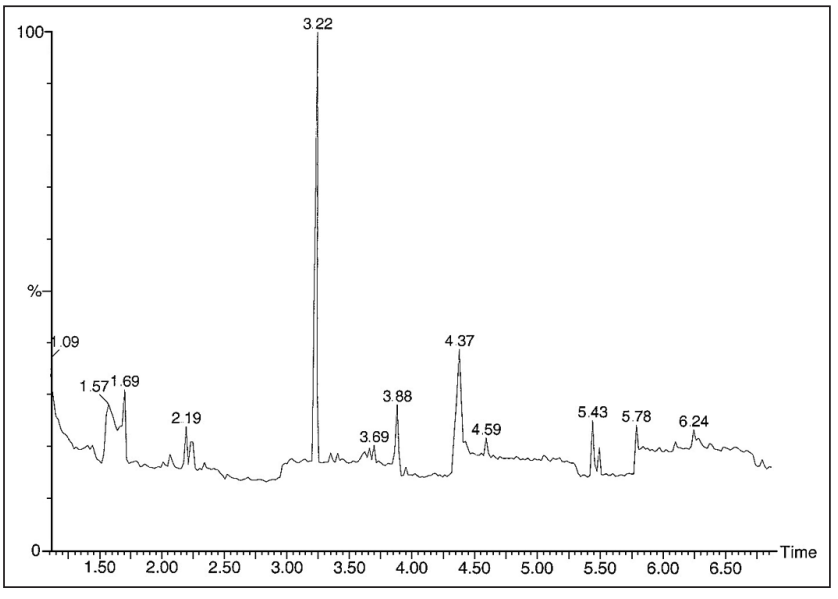

Figure 3: Gas chromatogram of a $0.5 \mu \mathrm{L}$ injection $X$. johnsonii ethyl acetate extract (dried and resuspended in methanol). Chromatography conditions were as described in the methods section 
[Downloaded free from http://www.jnatpharm.org on Wednesday, February 27, 2013, IP: 132.234.251.230] || Click here to download free Android application for this journal

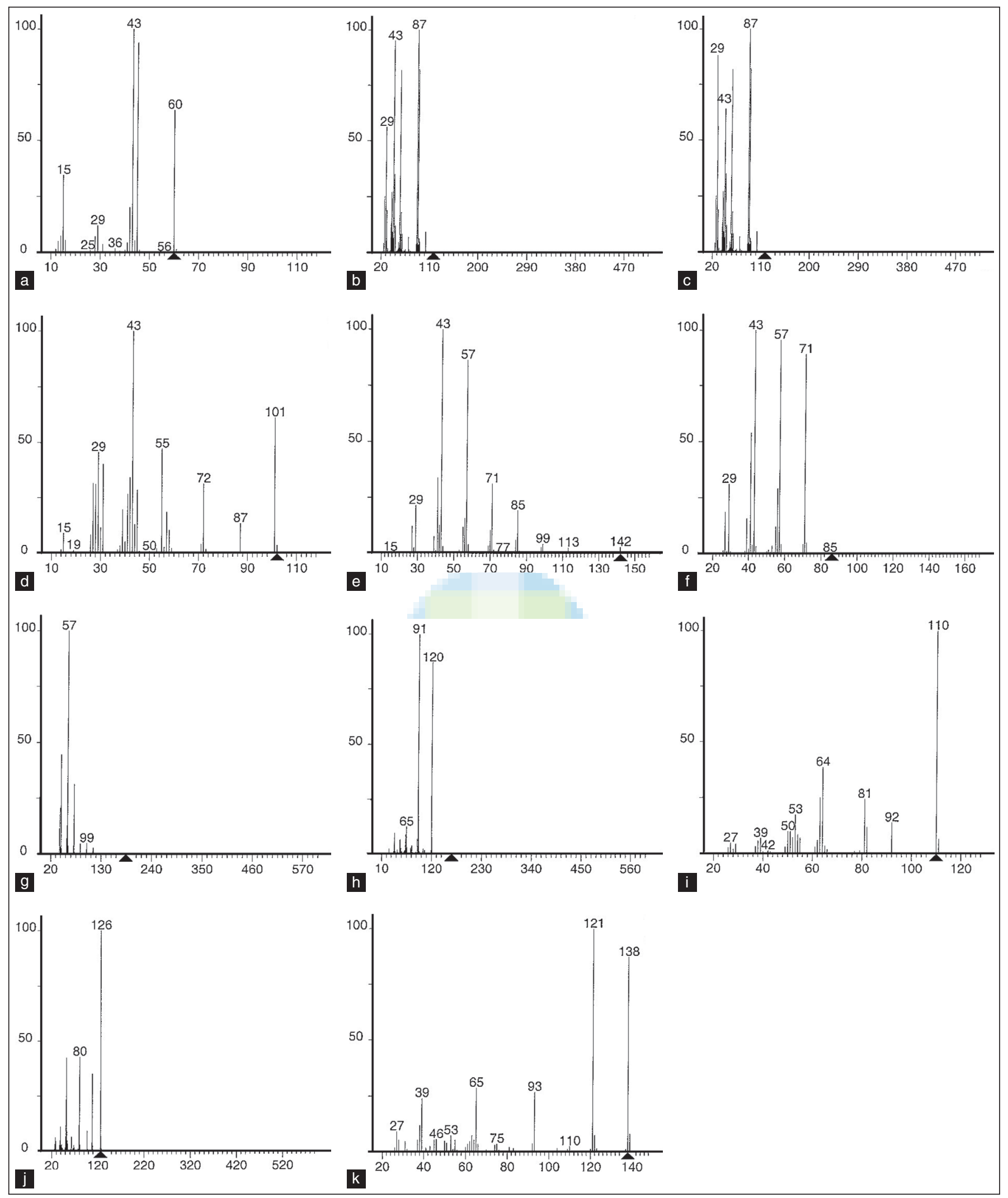

Figure 4: Mass spectra of $X$. johnsonii ethyl acetate extract peaks from GC separation. The spectra correspond to peaks from the GC chromatogram with retention times of (a) $1.09 \mathrm{~min}$, (b) $1.57 \mathrm{~min}$, (c) $1.69 \mathrm{~min}$, (d) $2.19 \mathrm{~min}$, (e) $3.22 \mathrm{~min}$, (f) $3.69 \mathrm{~min}$, (g) $3.88 \mathrm{~min}$, (h) $4.37 \mathrm{~min}$, (i) $4.59 \mathrm{~min}$, (j) $5.43 \mathrm{~min}$, (k) $5.78 \mathrm{~min}$ 
[Downloaded free from http://www.jnatpharm.org on Wednesday, February 27, 2013, IP: 132.234.251.230] || Click here to download free Android application for this journal

Cock and Kalt: Identification of anaesthetic components in Xanthorrhoea johnsonii leaf extracts

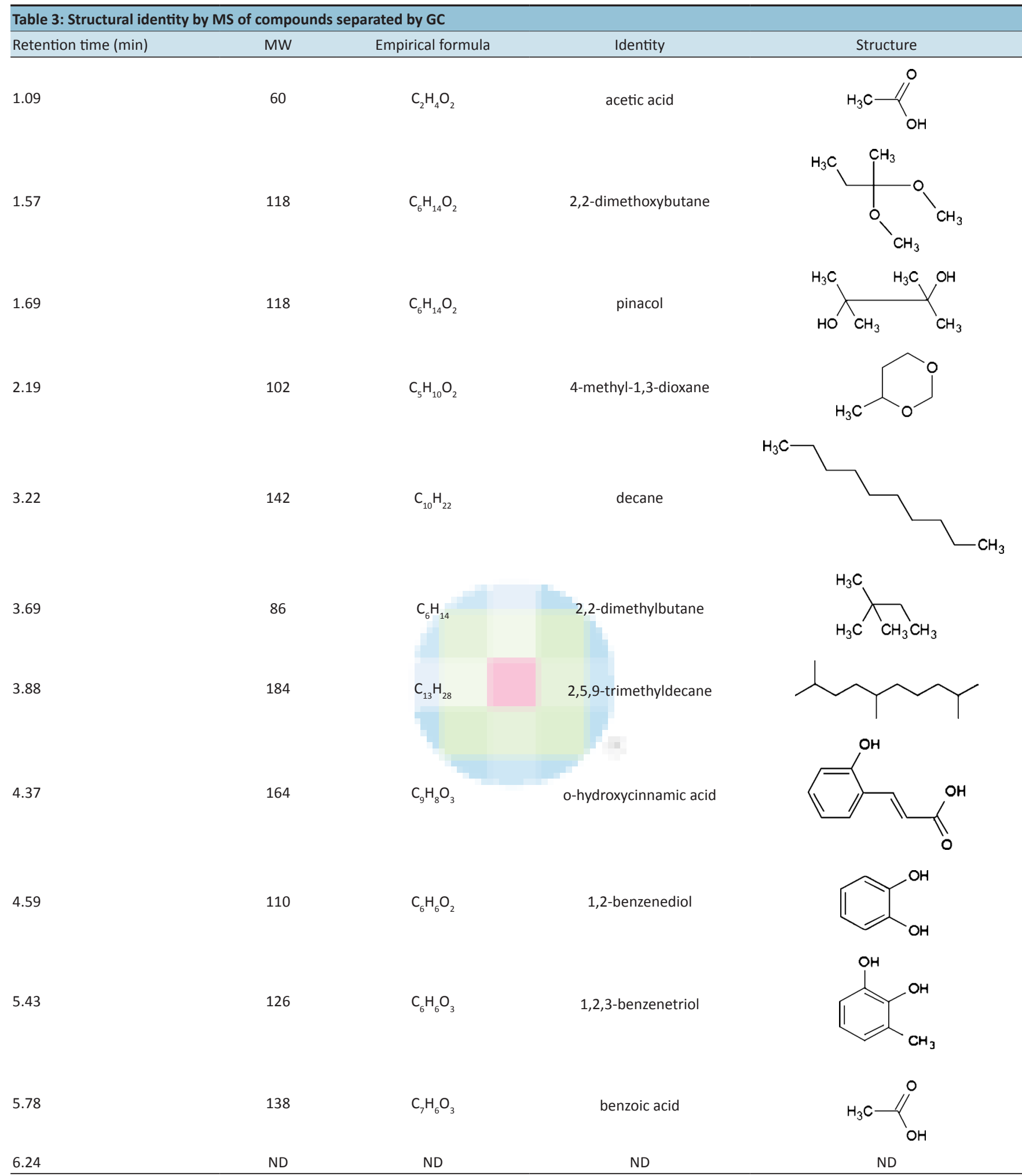

\section{DISCUSSION}

This study reports on the apparent anaesthetic effect of $X$. johnsonii methanol and ethyl acetate leaf extracts. This is in agreement with a previous study which reported on the apparent anaesthetic effect of a $X$. johnsonii methanolic leaf extract. ${ }^{[4]}$ In both the current and previous studies, brine shrimp nauplii exposed to the $X$. johnsonii methanol (and ethyl acetate in this study) leaf extracts 'died' following a $12 \mathrm{~h}$ exposure, only to 'recover' and swim 
[Downloaded free from http://www.jnatpharm.org on Wednesday, February 27, 2013, IP: 132.234.251.230] || Click here to download free Android application for this journal

Cock and Kalt: Identification of anaesthetic components in Xanthorrhoea johnsonii leaf extracts

normally by $48 \mathrm{~h}$ exposure. It appears that the $X$. johnsonii methanol and ethyl acetate leaf extracts have anaesthetic effects, possibly similar to those previously reported for tubocurarine, dimethyltubocurarine and alcuronium (collectively known as curare, a South American arrow poison) from Chondrodendron tomentosum ${ }^{[6]}$ from which the $A$. franciscana nauplii are able to temporarily recover. By $60 \mathrm{~h}$ the $X$. johnsonii methanol or ethyl acetate extract exposed nauplii were again experiencing difficulty in swimming ('strobe-like' swimming) and the \% apparent moribundity began to increase. The nauplii did not recover from this moribund state a second time.

Of the compounds detected by GC-MS in the bioactive $X$. johnsonii ethyl acetate leaf extract, several have been reported to have medicinally important bioactivities. Benzoic acid and its derivatives have previously been used in the treatment of fungal disorders including tinea, ringworm and athletes foot. ${ }^{[14,15]}$ They were also used as expectorants, analgesics and antiseptics until the early part of the $20^{\text {th }}$ century. ${ }^{[14,16]}$ Furthermore, sodium benzoate (a soluble benzoic acid salt) is used as a common antimicrobial preservative in foods, although it usage is limited to $\leq 0.1 \%$ due to its toxicity. ${ }^{[14,17]}$ Similarly, the benzene alcohols detected in the $X$. johnsonii ethyl acetate extract (1,2-benzenediol (catechol) and 1,2,3-benzenetriol (pyrogallol)) also have documented antiseptic properties. ${ }^{[14]}$ They are also powerful reducing agents and therefore have potential applications in protection against oxidative stress. Furthermore, catechol is also a component of some pesticides and a precursor for several pharmaceuticals. A literature search was unable to find any reports of anaesthetic/sedative effects for any of these compounds.

Several other compounds detected in the $X$. johnsonii ethyl acetate extract are toxic and may therefore contribute to the toxicity reported in this and previous studies. ${ }^{[4,5]}$ The unbranched (decane) and branched (2,5,9-trimethyldecane, 2,2-dimethylbutane) paraffins detected in this study have previously been reported to be toxic. ${ }^{[18]}$ The branched alcohol pinacol and the branched ether 2,2-dimethoxybutane have also been shown to be toxic. Similarly, acetic acid has previously been shown in our laboratory to induce mortality in A. franciscana nauplii and is routinely used to induce mortality in the assay prior to total nauplii counts. ${ }^{[19]}$

Of perhaps more interest is the presence of a hydroxycinnamic acid in the $X$. johnsonii ethyl acetate extract. Hydroxylated cinnamic acid derivatives have been shown to have a number of medicinally important bioactivities including antimicrobial, ${ }^{[20]}$ anti-inflammatory, ${ }^{[21]}$ antioxidant, antigenotoxic ${ }^{[22]}$ and gastroprotective ${ }^{[23]}$ bioactivities. Hydroxycinnamic acid is synthesised from the aromatic amino acids tyrosine and phenylalanine and may affect aromatic amino acid metabolism [Figure 5].

Aromatic amino acid metabolism can be regulated by feedback inhibition loops [Figure 5]. Tyrosine and phenylalanine have been shown to inhibit the enzyme chorismate mutase and thus inhibit their own production. ${ }^{[24]}$ As hydroxycinnamic acids are products of further tyrosine or phenylalanine metabolism, it is likely that hydroxycinnamic acids may also inhibit chorismate mutase. This would result in more chorismate being available to be converted to tryptophan and thus ultimately to serotonin. Therefore, the presence of increased levels of hydroxycinnamic acid may stimulate the production of higher levels of serotonin, which may in turn be responsible (at least in part) for the sedative/ anaesthetic effect seen in this study.

Interestingly, whilst o-hydroxycinnamic acid was detected in the ethyl acetate extract in this study, we did not detect serotonin. Extract derived serotonin may therefore not be responsible for the anaesthetic/sedative effect seen in A. franciscana. Instead, any increase in serotonin level may be due to the $A$. franciscana's own metabolism. Previous studies have demonstrated the ability of fasting Artemia salina (a species closely related to $A$. franciscana) to synthesise tyrosine and phenylalanine. ${ }^{[25]}$ Unfortunately that study did not report on the tryptophan levels in A. salina. Whilst not stated by the authors, it is likely that the A. salina tryptophan was destroyed

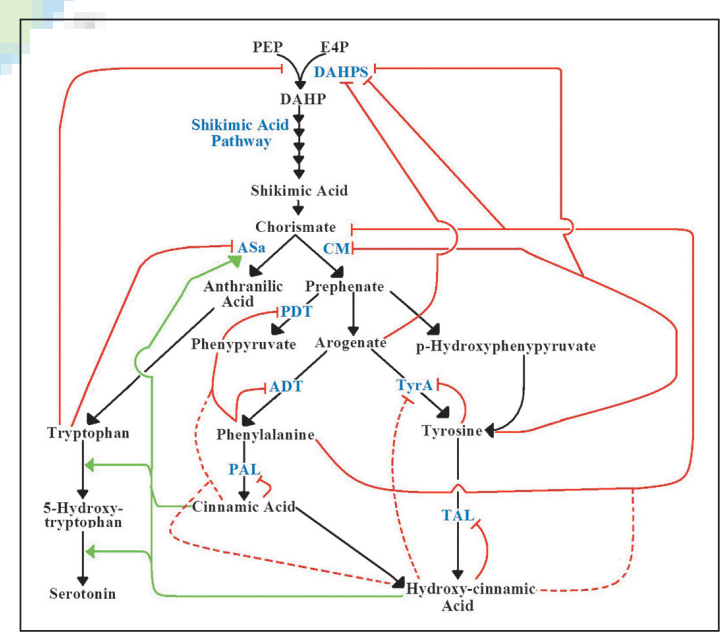

Figure 5: Schematic representation of the post-transcriptional regulation of the Shikimic acid pathway, aromatic amino acid metabolism and the production of serotonin, cinnamic acid and hydroxycinnamic acid. Key metabolites (black) and enzymes (blue) are shown. Known allosteric inhibition of compounds within the pathway is shown by red unbroken lines and putative allosteric inhibition with broken red lines. Putative activation is shown with green lines. PEP, phosphoenolpyruvate; E4P: Erythrose-4-phosphate, DAHP: 3-deoxy-d-aqrabino-heptulosonate-7-phosphate, DAHPS: 3-deoxy-daqrabino-heptulosonate-7-phosphate synthase, ASa: Anthranilate synthase, CM: Chorismate mutase, PDT: Prephenate dehydrogenase, ADT: Arogenate dehydratase, TyrA: Arogenate dehydrogenase, PAL: Phenylalanine ammonia lyase, TAL: Tyrosine ammonia lyase 
[Downloaded free from http://www.jnatpharm.org on Wednesday, February 27, 2013, IP: 132.234.251.230] || Click here to download free Android application for this journal

during the acid hydrolysis protocol used in that study and was thus unable to be detected. It is therefore possible that Artemia spp. may have the ability to synthesise their own tryptophan and further studies are required to determine if this is so. If indeed $A$. franciscana can synthesise tryptophan then it is possible that exposure to o-hydroxycinnamic acid in the ethyl acetate and methanol extracts may induce production of tryptophan in the A. franciscana by blocking chorismate mutase. Excess tryptophan may then be converted to serotonin, which in turn may result in the anaesthetic/sedative effect observed in our studies. Alternatively, o-hydroxycinnamic acid may directly modulate the conversion of endogenous tryptophan to serotonin with the same result.

o-Hydroxycinnamic acid may be produced by $X$. johnsonii as a defence against herbivores and its production may be up-regulated in response to other stresses. Similar defence responses exist in other plant species. Rice responds to pathogenic infection by enhancing anthranilate synthase (AS) which regulates flux through the tryptophan biosynthetic pathway. ${ }^{[26]}$ This results in increased serotonin production and incorporation into cell walls at the site of the lesion. Whilst that study did not examine the mechanism of AS activation, it may occur via a hydroxycinnamic acid induced blocking of chorismate mutase mechanism that we postulate to occur in $X$. johnsonii. Indeed, a different study has noted an increase in the levels of hydroxyl-cinnamic acids in the cell walls of pathogen challenged plants. ${ }^{[27]}$ Similarly, Avena sativa (oat) produces hydroxyl-cinnamic acid amides as phytoalexins in response to infections. ${ }^{[2]}$ Other stresses have also been shown to affect aromatic amino acid synthesis and their subsequent usage in the production of a variety of secondary metabolites including coumarins and other cinnamic acid derivatives, phenolic esters, quinines, indole derivatives, anthrocyanins and lignin. The production of aromatic secondary metabolites may be regulated by developmental stage, ${ }^{[29]}$ and environmental stimuli such as light and wounding ${ }^{[30]}$ as well as exposure to toxins. ${ }^{[31]}$

The $X$. johnsonii leaf samples examined in this study were collected in 2008 during a long period of drought in Australia. Perhaps these harsh conditions may have resulted in the $X$. johnsonii plants producing (or increasing production of) a stress related protective compound (possibly o-hydroxycinnamic acid). Indeed, Toohey Forest leaf samples from several $X$. johnsonii plants collected during this drought period have all provided the same trend reported here. In contrast, we have not detected this trend in the extracts of $X$. johnsonii leaf samples collected during periods of normal rain after the drought had ended (unpublished results). Previous studies into the aromatic amino acid metabolism of different plant species have reported that plants often react to stresses such as amino acid starvation or exposure to oxidative stress inducers by inducing the expression of the genes encoding for tryptophan biosynthetic enzymes. ${ }^{[24,32]}$ It is possible that other stresses such as water deprivation may induce similar responses, although this is yet to be determined. Whilst the current studies indicate that similar metabolic pathways may be involved in $X$. johnsonii protective mechanisms, biochemical verification is necessary. It would be of interest to determine whether other stresses induce similar responses in $X$. johnsonii and other related Xanthorrhoea species.

\section{CONCLUSIONS}

The results reported here confirm the toxicity of $X$.johnsonii leaf components and the apparent anaesthetic/ sedative effects previously reported for methanolic leaf extracts. This study extends the earlier study, testing a range of solvents with different polarities. An apparent anaesthetic effect and toxicity were detected in both the methanol and ethyl acetate extracts. As the ethyl acetate extract appeared to be less complex (as determined by RP-HPLC analysis) it was further analysed by GC-MS, resulting in the separation of 12 main components. Of these, 11 compounds were identified, with the compound most likely to be responsible for the observed anaesthetic/sedative effect being o-hydroxycinnamic acid. Further studies are required to confirm that authentic o-hydroxycinnamic acid has the effects described here. Similarly, mechanistic studies are required to determine whether the anaesthetic/sedative effect is induced by the mechanism postulated in this report.

\section{ACKNOWLEDGMENTS}

Financial support for this work was provided by School of Biomolecular and Physical Sciences, Griffith University.

\section{REFERENCES}

1. Borsboom AC. Xanthorrhoea: A review of current knowledge with a focus on X. johnsonii and X. latifolia, two Queensland protected plantsin-trade. Environmental Protection Agency: Queensland; 2005.

2. Bülow-Olsen A, Just J, Liddle MJ. Growth and flowering history of Xanthorrhoea johnsonii Lee (liliaceae) in Toohey Forest Queensland. Bot J Linn Soc 1982;84:195-207.

3. McKenzie R. Australian native poisonous plants. Australian Society for Growing Australian Plants (Australia); 1997. http://farrer.csu.edu.au/ ASGAP?Apol7/sep97-4.html; Accessed 12 January 2010.

4. Cock IE, Kalt FR. Toxicity evaluation of Xanthorrhoea johnsonii leaf methanolic extract using the Artemia franciscana bioassay. Pharmacogn Mag 2010;6:166-71.

5. Kalt FR, Cock IE. The medicinal potential of Australian native plants from Toohey Forest, Australia. SPJNS 2010;28:41-7.

6. Bisset NG. War and hunting poisons of the New World. Part 1. Notes on the early history of curare. J Ethnopharmacol 1992;36:1-26.

7. Strecker GJ, Jackson MB. Curare binding and the curare-induced subconductance state of the acetylcholine receptor channel. Biophys J 1989;56:795-806. 
[Downloaded free from http://www.jnatpharm.org on Wednesday, February 27, 2013, IP: 132.234.251.230] || Click here to download free Android application for this journal

8. Coutts RH, Catterall CP. Identifying the plants of Toohey Forest. Ecos Educational Publishers: Nambour, Australia; 1980.

9. Kukkonen L, Cock IE. An examination of the medicinal potential of Scaevola spinescens: Toxicity, antibacterial and antiviral activities. Pharmacog Res 2011;3:85-94.

10. Vesoul J, Cock IE, An examination of the medicinal potential of Pittosporum phylliraeoides: Toxicity, antibacterial, and anfungal activities. Pharmacog Commun 2011;1:8-17.

11. Cock IE. High performance liquid chromatographic separation and identification of a toxic fraction from Aloe barbadensis Miller leaf gel using the Artemia nauplii bioassay. Internet J Toxicol 2008;4:2.

12. Ruebhart DR, Wickramasinghe W, Cock IE. Protective effect of the antioxidants vitamin E and Trolox against Microcystis aeruginosa and microcystin-LR in Artemia franciscana nauplii. J Toxicol Environ Health A 2009;72:1567-75.

13. Cock IE, Ruebhart DR. Comparison of the brine shrimp nauplii bioassay and the ToxScreen-II test for the detection of toxicity associated with Aloe vera (Aloe barbadensis Miller) leaf extract. Pharmacog Res 2009; 1:102-8.

14. Cowan MM. Plant products as antimicrobial agents. Clin Microbiol Rev 1999;12:564-82.

15. Lago JH, Ramos CS, Casanova DC, Morandim AA, Bergamo DC, Cavalheiro AJ, et al. Benzoic acid derivatives from Piper species and their fungitoxic activity against Cladosporium cladosporioides and C. Sphaerospermum. J Nat Prod 2004;67:1783-8.

16. Wilson CO, Gisvold O, Block JH. Wilson and Gisvold's Textbook of Organic Medicinals and Pharmaceuticals. Lippincott Williams and Wilkins: 2004.

17. Bateman B, Warner JO, Hutchinson E, Dean T, Rowlandson P, Gant C, et al. The effects of double blind, placebo controlled, artificial food colourings and benzoate preservative challenge on hyperactivity in a general population sample of preschool children. Arch Dis Child 2004;89:506-11.

18. Sikkema J, de Bont JA, Poolman B. Mechanisms of membrane toxicity of hydrocarbons. Microbiol Rev 1995;59:201-22.

19. Sirdaarta J, Cock IE. Vitamin E and Trolox ${ }^{\mathrm{TM}}$ reduce toxicity of Aloe barbadensis Miller juice in Artemia franciscana nauplii but individually are toxic at high concentrations. Internet J Toxicol 2008;5:1-13.

20. Cho JY, Moon JH, Seong KY, Park KH. Antimicrobial activity of 4-hydroxybenzoic acid and trans 4-hydroxycinnamic acid isolated and identified from rice hull. Biosci Biotechnol Biochem 1998;62:2273-6.
21. Nagasaka R, Chotimarkorn C, Shafiqul IM, Hori M, Ozaki H, Ushio H. Anti-inflammatory effects of hydroxycinnamic acid derivatives. Biochem Biophys Res Commun 2007;358:615-9.

22. Ferguson LR, Zhu ST, Harris PJ. Antioxidant and antigenotoxic effects of plant cell hydroxycinnamic acid in cultured HT-29 cells. Mol Nutr Food Res 2005;49:585-93.

23. Nanjundaiah SM, Annaiah HN, Dharmesh SM. Gastroprotective effect of ginger rhizome (Zingiber officinale) extract: Role of gallic acid and cinnamic acid in $\mathrm{H}^{+}, \mathrm{K}^{+}$-ATPase/H. pylori inhibition and anti-oxidative mechanism. Evid Based Complement Alternat Med 2011:1-13.

24. Tzin V, Galili G. The biosynthetic pathways for shikimate and aromatic amino acids in Arabidopsis thaliana. The Arabidopsis Book. American Society of Plant Biologists 2010;8: http://www.bioone.org/doi/ full/10.1199/tab.0132 (accessed 30 Nov 2011).

25. Dabrowski K, Rusiecki M. Content of total and free amino acids in zooplanktonic food of fish larvae. Aquaculture 1983;30:31-42.

26. Ishihara A, Hashimoto Y, Tanaka C, Dubouzet JG, Nakao T, Matsuda F, et al. The tryptophan pathway is involved in the defense responses of rice against pathogenic infection via serotonin production. Plant J 2008;54:481-95.

27. Graça J, Santos S. Linear aliphatic dimeric esters from cork suberin. Biomacromolecules 2006;7:2003-10.

28. Miyagawa $\mathrm{H}$, Ishihara $\mathrm{A}$, Nishimoto $\mathrm{T}$, Ueno $\mathrm{T}$, Mayama $\mathrm{S}$. Induction of avenanthramides in oat leaves inoculated with crown rust fungus, Puccinia coronate f. sp. avenae. Biosci Biotechnol Biochem 1995;59:2305-6.

29. Whetten R, Sederoff R. Lignin Biosynthesis. Plant Cell 1995;7:1001-13.

30. Weaver LM, Herrmann KM. Dynamics of the shikimate pathway in plants. Trends Plant Sci 1997;2:346-51.

31. Sharon A, Amsellem Z, Gressel J. Glyphosate suppression of an elicited defense response: Increased susceptibility of Cassia obtusifolia to a Mycoherbicide. Plant Physiol 1992;98:654-9.

32. Zhao J, Williams CC, Last RL. Induction of Arabidopsis tryptophan pathway enzymes and camalexin by amino acid starvation, oxidative stress, and an abiotic elicitor. Plant Cell 1998;10:359-70.

Cite this article as: Cock IE, Kalt FR. Gas chromatography-mass spectroscopy analysis of a Xanthorrhoea johnsonii leaf extract displaying apparent anaesthetic effects. J Nat Pharm 2012;3:78-88

Source of Support: School of Biomolecular and Physical Sciences, Griffith University. Conflict of Interest: None declared. 